\title{
Feasibility Demonstration of the Effective Design of the Opener Group of the Seeder for Winter Wheat in Arid Conditions
}

\author{
Vladimir Milyutkin*, Sergey Zhiltsov, Igor Guzhin, Dmitry Sazonov, and Evgeny Artamonov \\ Samara State Agrarian University, 2, Uchebnaya St., 446409, Ust-Kinelskiy, Russia
}

\begin{abstract}
The article is devoted to improving the winter wheat seeding technology. Choosing the rational design of the opener group enables the placement of crop seeds in a deeper moisty soil layer for their rapid germination with the formation of a surface relief from furrows. Seeds are placed into furrows at the optimal depth 4-5 cm and furrow slices are formed by the soil thrown out of the furrow by chisel-shaped openers and compacted by individual rollers for each opener. That solves the problem of insufficient soil moisture in arid regions.
\end{abstract}

\section{Introduction}

\subsection{Relevance}

The main grain products in Russia are winter crops, in particular wheat. In order to get high productivity, the winter wheat sown in autumn has to give full-fledged seedlings and sprouts for overwintering and successful development in a spring-summer period. However, the conditions for seeding in arid zones that include the regions of the Volga region (Samara oblast and others) are very often unfavourable because of the low moisture content of the topsoil treated during the summer that requires the improvement of the plant production technology of winter crops [1-6].

This situation is accompanied by the global problems of food shortages, first, of grain crops, world's population growth, and an increase in the frequency of negative weather events, which are primarily associated with the so-called global warming.

\subsection{Aim of the study}

The aim of the study was to summarize the world scientific and industrial experience and our own research carried out at Samara State Agrarian University (Russia) in order to substantiate the most effective winter crop seeding technologies in arid conditions using the most rational combination and design of work tools in the opener group of the seeder.

\section{Results and discussion}

The climatic characteristics of the Volga region (including Samara oblast) are characterized by an arid summer-autumn cycle. After the sowing winter crops, the seedlings are often late, sparse, with an insufficient degree of tillering. However, this peculiarity, as practice shows, is more typical only of the seeders with doubledisc openers, while chisel openers contribute to good early shoots. According to the deep analysis of the seeders used in Russian agro-industrial complex and produced in the Russian Federation (Samara) by Eurotechnika JSC of the German company AmazonenWerke, there is a large range of seeders for such important technological operation in agriculture as sowing. Long-term joint scientific work of Samara State Agrarian University with the Amazone company on many of its agricultural machines [6-8], to a greater extent on seeders both for traditional technology (D9, Citan), and for conservation technlogies No-Till, Minitill (Primera DMC, Condor, Cauena) [7], allows us to recommend the most effective seeders for each specific soil and climatic conditions and crops. And today, this, along with the widely used DMC seeder used in the Russian Federation, there is a seeder for both direct seeding and traditional technologies - Condor with a working width of 12 and 15 meters [7-8], productivity 725 hectares / hour at a working speed of up to $14 \mathrm{~km} / \mathrm{h}$, and seasonal production on spring and winter crops up to 2,000 hectares (Fig. 1).

The Condor seeder sows with ConTeC pro chisel openers with individual suspension and row spacing of $25 \mathrm{~cm}$ and $31.3 / 33.3 \mathrm{~cm}$. What is most important - a roller works behind each opener - a rubberized support wheel, which compacts and improves contact of the sown seeds with the soil, while moisture is pulled through the capillaries from the lower-lying wetter layers. Thereby it contributes to early emergence of seedlings, which later get natural autumn precipitation and receive favorable conditions for tillering and providing a good harvest.

\footnotetext{
Corresponding author: oiapp@mail.ru
} 

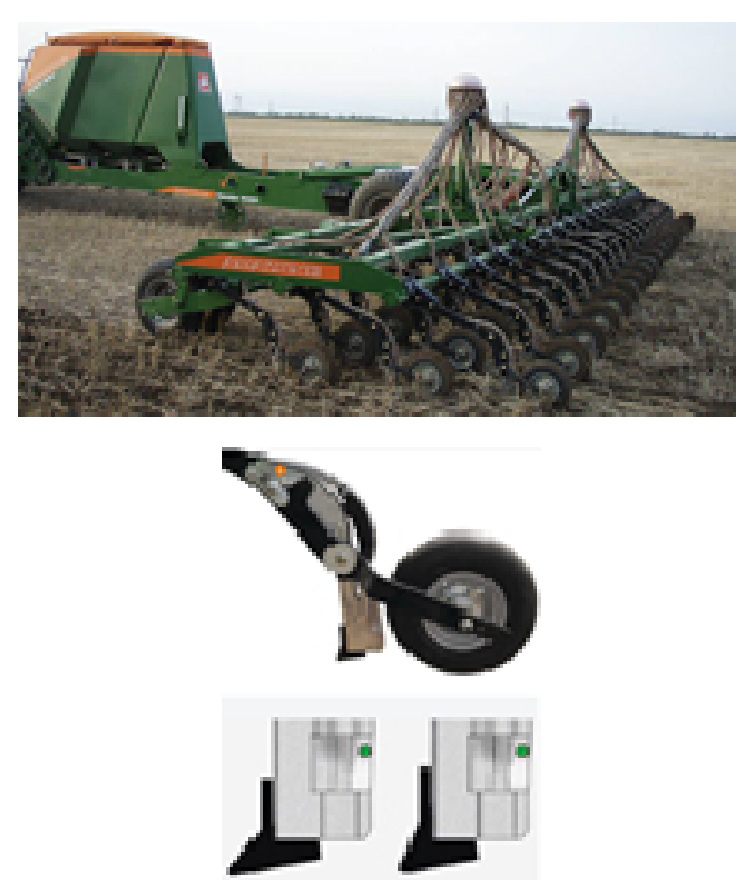

Fig. 1. Direct seeding machine Condor with chisel openers and press roller.

The Condor seeder sows with ConTeC pro chisel openers with individual suspension and row spacing of $25 \mathrm{~cm}$ and $31.3 / 33.3 \mathrm{~cm}$. What is most important - a roller works behind each opener - a rubberized support wheel, which compacts and improves contact of the sown seeds with the soil, while moisture is pulled through the capillaries from the lower-lying wetter layers. Thereby it contributes to the amicable and early emergence of seedlings, which later get natural autumn precipitation and receive favorable conditions for tillering and providing a good harvest. This combination of a chisel opener and a supporting rubberized wheel roller creates a profile surface of the field, where plants grow and develop in the furrows, protected from wind and drying by the ridges of the soil. Thus, with the use of this seeder, intensive technologies for the cultivation of winter cereals in arid regions with a moderately continental climate are possible [9-15].

With a working width of $12 \mathrm{~m}$ and $15 \mathrm{~m}$ and a volume of a 3-section pressurized tank of 8,000 1, the Condor seeder provides high seeding quality even with a lack of moisture, and with low traction resistance significant productivity. A particularly distinctive and more favorable design feature of the Condor seeder is the location of the large-volume grain tank in front of the seeder, which ensures the safety of the protective soil ridges without being destroyed by the tank support wheels.

In our study, sowing of winter wheat of the Svetoch variety of the Samara Research Institute of Agriculture was carried out on August 27, 2019 with a DMC Primera seeder. Due to the dry topsoil ( $\mathrm{W}=13-14 \%)$, it was carried out to a greater than optimal $(4-5 \mathrm{~cm})$ depth into a moisty soil layer of $8-10 \mathrm{~cm}$ with a rate of 3.5 million seeds per hectare. The greater depth of $8-10 \mathrm{~cm}$ allowed seeds to germinate 6-8 days earlier compared to seeds sown at an optimal depth of 4-5 $\mathrm{cm}$ but into a dry soil layer with a disc seeder D-9.

Due to the insufficient amount of summer precipitation (in May-September 2019, only $87.8 \mathrm{~mm}$ precipitation, $30.2 \%$ fell in the form of rain compared with the average annual $239 \mathrm{~mm}$ ), the soil in the upper layer was dry. In the upper layer $0-10 \mathrm{~cm}$, the relative soil moisture was $13.5-14.0 \%$, but due to the more moisty soil in the middle layer $10-20 \mathrm{~cm}$ (soil moisture was $18.0 \%$ ) and seeds sown in this layer, the seedlings turned out to be satisfactory, especially in the deeper, lower layers $20-30 \mathrm{~cm}$, the humidity was $23 \%$.

According to B.I. Verigo, winter wheat seeds begin to germinate when the soil moisture on the "seed lane" is higher than $16-17 \%$. With a moisture content of $13-15 \%$, the seeds do not germinate, which nevertheless explains some late sprouting of winter wheat in experiments only after a sufficiently large amount of autumn precipitation and on the basis of his studies, a model was created (Fig.2, Fig. 3) to determine the optimal sowing depth into the wet layer.

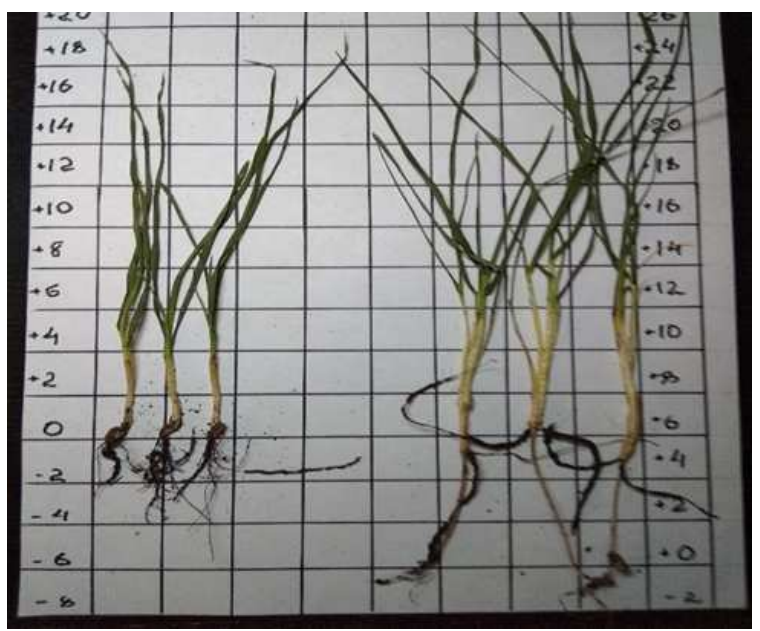

Fig. 2. Root system and seedlings of winter wheat.

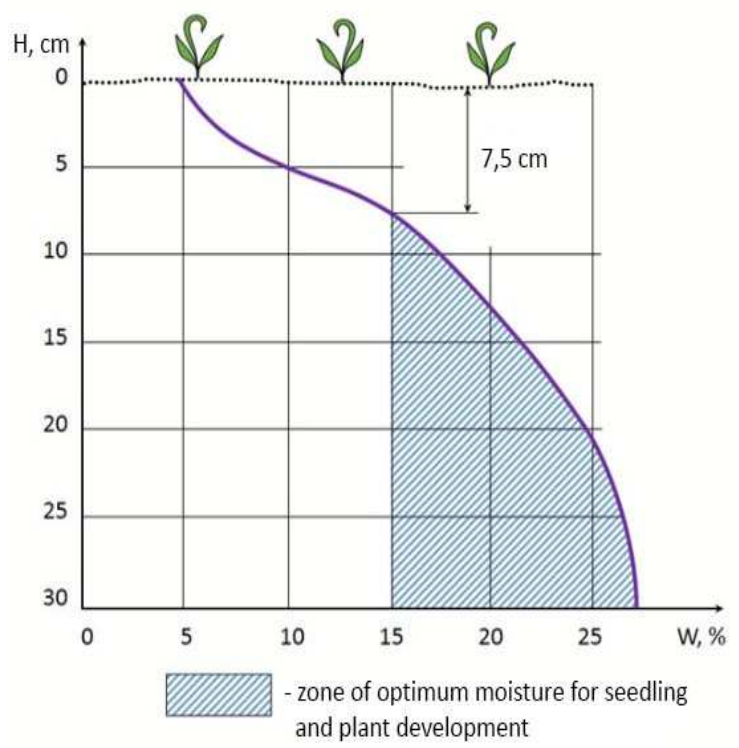

Fig. 3. Model for choosing the seeding depth according to the optimal soil moisture. 
The opener group of the Condor seeder very successfully solves this problem. Chisel openers even set for sowing seed on 10-12 cm into wet soil, throw part of the soil from the furrow during their passage, forming a ridge, while the seeds are placed in one horizon at the bottom of the wet furrow, creating the most favourable conditions for their germination. The rubberized support wheel driving behind the opener compacts the crumbling soil and forms a furrow-ridge, while the seeds are embedded at an optimal depth of 4-6 $\mathrm{cm}$ into a wet layer with good contact with the soil and germinate without difficulty enough quickly, which ensures their good preparation for overwintering due to optimal tillering (Fig. 4).
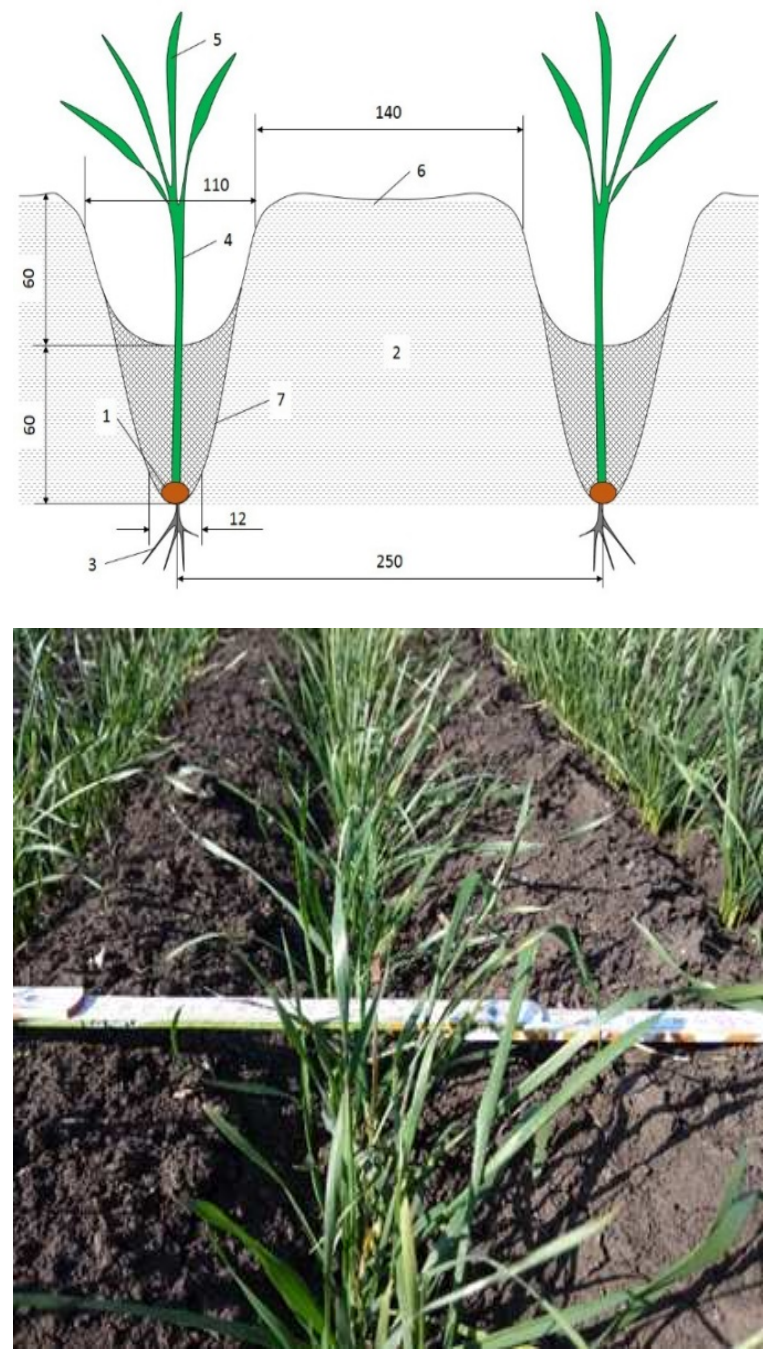

Fig. 4. Analytical and practical sowing profiles with the Condor seeder.

We observed the data of production crops in good condition of winter wheat using the Condor 15000 seeder at the agricultural enterprise "Ali" in Krasnoarmeisky district of Samara oblast (Fig. 5, Fig. 6).

When using the Condor 15000 seeder and a seed rate of $175 \mathrm{~kg} / \mathrm{ha}$, the row spaces were set at $25 \mathrm{~cm}$, which ensured good autumn tillering and further development of winter wheat crops of the local "Resurs" variety by selection of the Samara Research Institute of Agriculture.

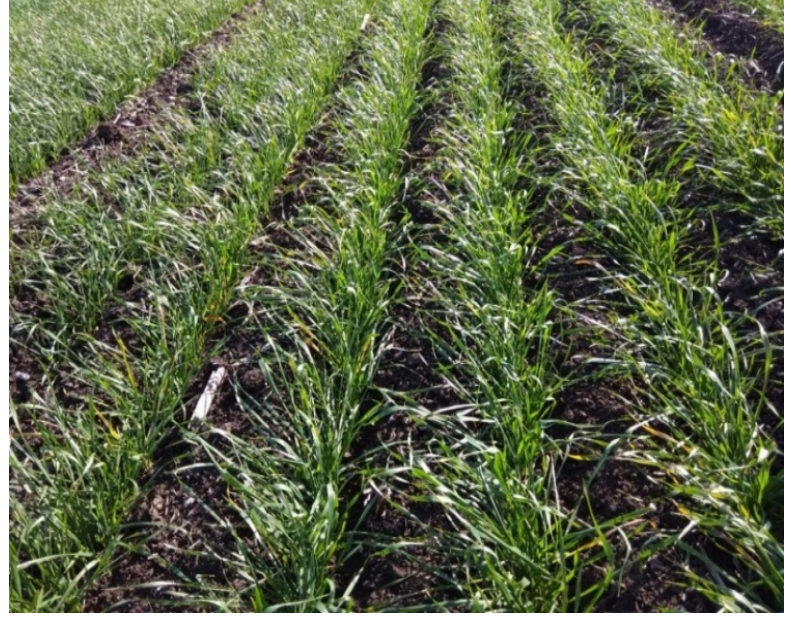

Fig. 5. Winter wheat seedlings of 10/3/2019 at the agricultural enterprise "Ali" (Samara oblast), sown with a Condor seeder.

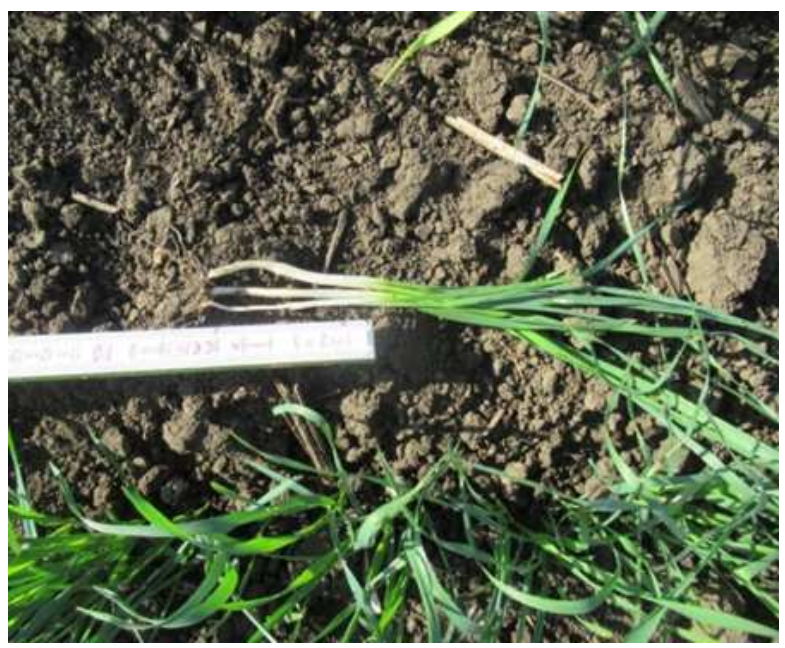

Fig. 6. The depth of seeding $(5-6 \mathrm{~cm})$ of sprouted winter wheat.

Due to the peculiarities of sowing seeds strictly to the bottom of the furrow in a moisty soil layer with an optimal seeding depth with the chisel openers of the Condor seeder, the seedlings were friendly and early in contrast to sowing with disc openers (Fig. 7).

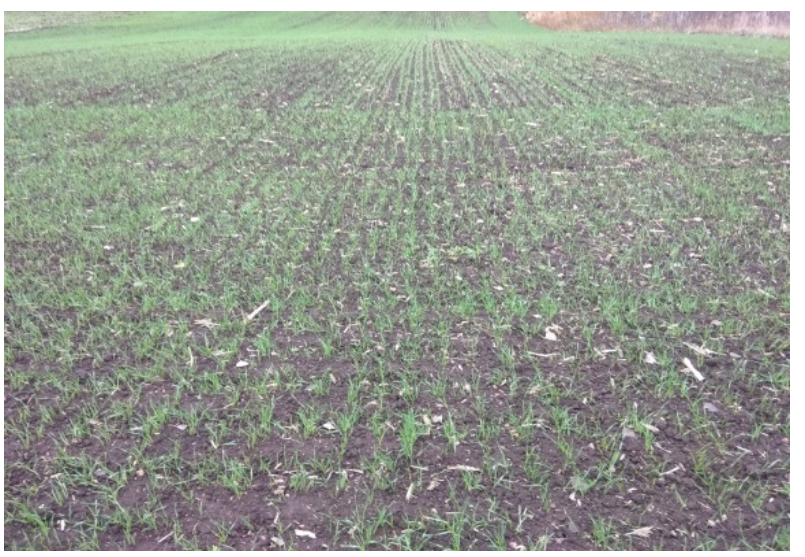

Fig. 7. Winter wheat seedlings sown in insufficiently moistened soil with disc openers at the same time as with chisel openers of Condor seeder. 
When sowing with disc openers with an acute lack of soil moisture, the seeds are located at different depths (Fig. 8a), falling into the dry soil layer. Therefore, the seedlings become thinned, only partially straightened by autumn precipitation with a certain lag behind the earlier seedlings, placed strictly at the same depth by chisel openers with sufficient moisture for seed germination (Fig. 8b). At the same time, the depth of pre-sowing soil treatment determines the depth of seeding with discs.

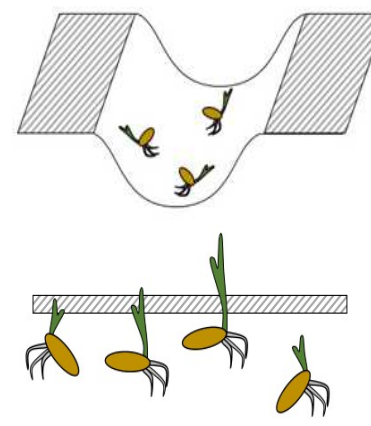

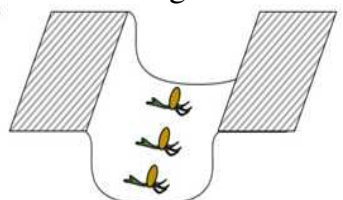

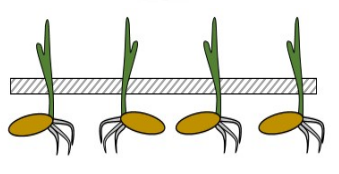

b
Fig. 8. Seeds in the furrow after the disc (a) and chisel (b) openers.

Thus, despite disc and chisel openers in spring are practically equivalent (except for traction resistance) under the sufficient soil moisture conditions, in autumn, when seeding winter crops with insufficient soil moisture, chisel openers with rubberized support wheels and a ridge-furrow technology provided by the Condor seeder, significantly surpass the disc ones as for creating better conditions for seed germination, seedling development and tillering necessary for overwintering.

We observed data of excellent production sowing of winter wheat using the Condor 15000 seeder at the agroenterprise "Ali" in Krasnoarmeisky district of Samara oblast (Fig. 9). Also, this agricultural enterprise is successfully switching to the use of liquid fertilizers. In particular, on the entire area of winter crops on the farm, spring fertilizing in the tillering stage was carried out with a concentrated solution of UAN-32 produced by KuibyshevAzot JSC with a rate of 100 liters per 1 hectare by sprayers of JSC Eurotechnika. Earlier, the spring fertilizing of winter crops on the farm was carried out with solid mineral fertilizers - ammonium nitrate, followed by harrowing with medium tooth harrows BZSS-1.0.

Fig. 9 (a, b, c) shows the common types of winter wheat variety "Resurs" by selection of the Samara Research Institute of Agriculture: a - seedlings on October 3, 2019, b - overwintered crops on April 15, 2020, c - "Resource" variety, processed in the spring of 2020 in the tillering phase by urea-ammonia mixture UAN-32 (nitrogen content N-32\%) before harvesting.

Adequate tillering of winter wheat ensured the formation of 367 productive stems per $1 \mathrm{~m}^{2}$ and a biological yield of $45.5 \mathrm{c} /$ ha (with an average for the region $-37.2 \mathrm{c} / \mathrm{ha}$ ) of the III quality class with a high selling price and production efficiency in the agricultural enterprise "Ali" of Krasnoarmeisky district of Samara oblast.
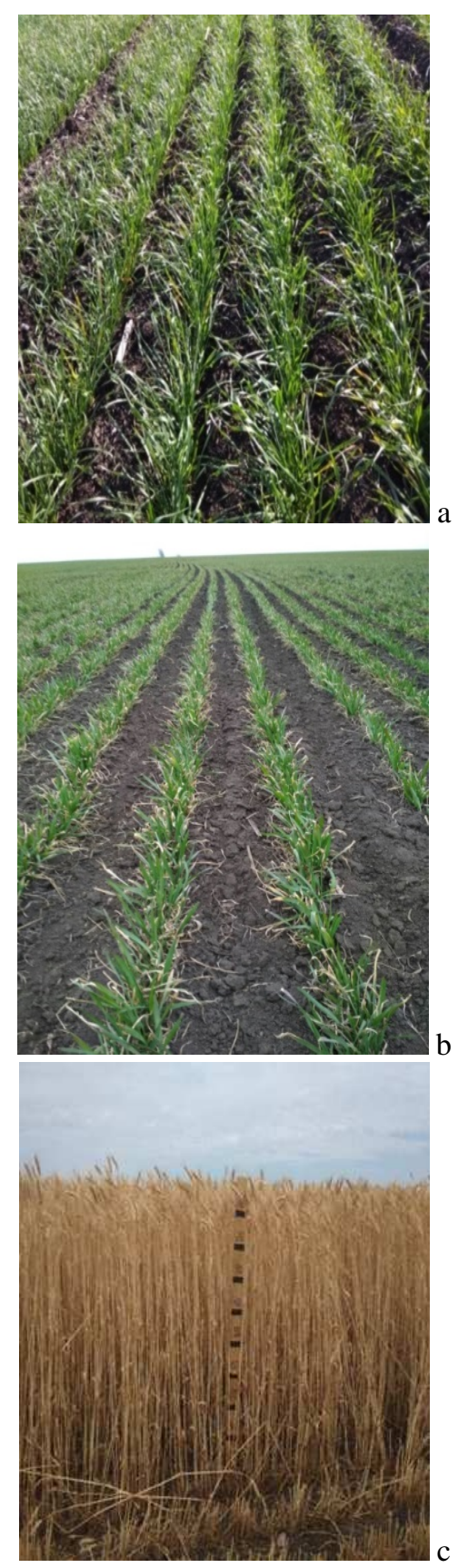

Fig. 9. Wheat variety "Resurs", sown with the Condor seeder: a - seedlings on October 3, 2019; b - overwintered crops on April 15, 2020; c - before harvesting on July 15, 2020 (yield 45.5 c / ha)

\section{Conclusions}

1. In a significant number of regions of the Russian Federation, including the Volga region, which is experiencing moisture stress, especially during the periods of sowing and development of agricultural crops (winter wheat), the most effective technologies are conservation technologies No-Till, Mini-Till and corresponding to them agricultural equipment - first of all, seeders.

2. Of the well-known and widespread seeders of direct and mulch seeding in the Russian Federation, good results are shown by seeders manufactured in 
Samara (JSC Eurotechnika of the German company AMAZONEN-Werke) Primera DMC, Condor, Cauena, and especially Condor for sowing winter crops in drought.

\section{References}

1. V.Ya. Goltyapin, Analysis of test results of seeders and direct sowing systems, Machinery and equipment for the village, 10 (268), 20-24 (2019)

2. R.A. Bulavintsev, Analysis of the design of openers of modern seeders for direct seeding of agricultural crops, Agrotechnics and energy supply, 2 (19), 8591 (2018)

3. E.V. Priporov, G.E. Samurganov, Analysis of the openers of grain seeders using resource-saving technology, in: Scientific support of the agroindustrial complex. Collection of abstracts based on the materials of the All-Russian (national) conference, pp. 207-208 (2019)

4. D.A. Yakovlev, V.I. Belyaev, R.E. Prokopchuk, Comparative energy assessment of the working bodies of seeding machines for direct sowing in different soil moisture conditions, Bulletin of Altai State Agrarian University, 6 (188), 144-150 (2020)

5. V.I. Belyaev, T. Meinel, N.V. Rudev, L.Ch. Grunwald, L.V. Sokolova, V.N. Kuznetsov, A.V. Matsyura, Influence of row spacing and seeding rate on crop yields cultivated by No-Till technology in Kulunda steppe (ALTAI region), Ukrainian Journal of Ecology, 2(3), 335-338 (2019)

6. V.A. Milyutkin, V.N. Sysoev, A.P. Trots, I.N. Guzhin, S.N. Zhiltsov, Technical and technological operations for the adaptation of agriculture to global warming conditions, BIO Web of Conferences, 17, 00075 (2020)

7. V.A. Milyutkin, V.A. Shakhov, A.S. Putrin, Yu.S. Ignatieva, V.I. Mirkitanov, The predominant efficiency of the Condor seeders with chisel openers when sowing winter crops with a lack of moisture in the surface layer soil, Bulletin of Orenburg State Agrarian University, 3 (83), 163-169 (2020)
8. V.A. Milyutkin, V.E. Buxmann, Effective technical and technological seeding complex - Condor of Russian production (JSC "Eurotechnika" - Samara) for sowing winter crops with insufficient soil moisture, AgroForum, 3, 64-67 (2020)

9. L. Mueller, V.G. Sychev, V. Romanenkov et al., Innovations and knowledge transfer for achieving landscape sustainability, In: Novel Methods and Results of Landscape Research in Europe, Central Asia and Siberia. Monograph in 5 volumes. V.G. Sychev, L. Müller (eds.), pp. 25-42 (Moscow, 2018)

10. Yu.F. Lachuga, I.V. Savchenko, P.A. Chekmarev et al., Water-accumulating technologies, soil treatment techniques and the use of mineral fertilizers in extreme conditions (Ryazan, 2014).

11. A.F. Zhuk, New methods of graded tillage, Agricultural machines and technologies, 4, 13-18 (2014)

12. V.V. Alt, S.P. Isakova, E.A. Lapchenko, The mathematical model of forming of optimal combination of machinery and tractor park subject to social factor, In: $13 T h$ international science technical conference on actual problems of electronic instrument engineering (APEIE - 2016). Proceedings: in 12 volumes, pp. 523-526 (2016)

13. V.A. Sidorova, E.E. Zhukovskii, P.V. Lekomtsev, V.V. Yakushev, Geostatistical analysis of the soil and crop parameters in a field experiment on precision agriculture, Eurasian Soil Science, 45(8), 783-792 (2012)

14. V.P. Yakushev, V.M. Bure, V.V. Yakushev, A.V. Bure, Theoretical basis of optimal choice of crop varieties, Russian Agricultural Sciences, 38(1), 1-3 (2012)

15. D. Kurtener, V. Yakushev, E. Krueger, H.A. Torbert, Zoning of an agricultural field using a fuzzy indicator model, In the collection: Precision Agriculture 2011 - Papers Presented at the 8th ECPA 2011, 8, 157-163 (2011) 